\title{
O ENSINO COMO ARTE NARRATIVA
}

Paulo Jorge SANTOS

Departamento de Filosofia, Faculdade de Letras da Universidade do Porto

pjsosantos@sapo.pt

\begin{abstract}
Resumo
Devemos ao psicólogo Jerome Bruner a distinção entre cognição paradigmática e cognição narrativa, duas formas que os seres humanos usam para entender o mundo e atribuir significado à sua existência. A cognição paradigmática recorre a conceptualizações ou a categorizações que se organizam tendo em vista atingir um ideal de descrição e explicação da natureza lógico-formal. Ela centra-se em modelos que isolam as causas gerais dos fenómenos e procura identificar procedimentos suscetíveis de corroborar ou infirmar hipóteses empiricamente testáveis alicerçadas em processos lógico-dedutivos. Na cognição narrativa, por seu turno, a realidade é compreendida através de histórias. Através de um enredo presente na narrativa a ação de um ou mais personagens estrutura-se no espaço e no tempo e confere significado à existência. A utilização de narrativas suscetíveis de funcionarem como elementos catalisadores da aprendizagem tem vindo a configurar um campo particularmente interessante ao nível da educação designado por ensino narrativo. Neste artigo descrever-se-ão os princípios genéricos suscetíveis de estruturar uma abordagem narrativa ao nível do ensino, como o espaço de aula pode tornar-se um local de partilha de narrativas e de co(construção) de significados e os resultados de investigações que evidenciam a sua eficácia ao nível da aprendizagem de conteúdos e do desenvolvimento de competências pelos estudantes.
\end{abstract}

Palavras-chave: cognição narrativa, cognição paradigmática, ensino narrativo

\begin{abstract}
We owe the psychologist Jerome Bruner the distinction between paradigmatic cognition and narrative cognition, two forms humans use to understand the world and to give meaning to their existence. Paradigmatic cognition resorts to conceptualizations or categorizations that are organized so as to achieve an ideal of description and explanation of logical-formal nature. It focuses on models that isolate the general causes of phenomena and seeks to identify procedures that can corroborate or reject empirically testable hypotheses based on logicaldeductive processes. In narrative cognition, reality is understood through good stories. Through a plot in the narrative, the action of one or more characters is structured in space and time and gives meaning to existence. The use of narratives that can be used as catalysts for learning has been a particularly interesting field in education called narrative teaching. In this article, I will describe the generic principles that can be used to structure a narrative approach at the level of teaching, and how the classroom can become a place to share narratives and to co-build meanings. I will also present the results of research and studies that show their effectiveness in terms of content learning and the development of competences in the students.
\end{abstract}

Keywords: narrative cognition, paradigmatic cognition, narrative teaching 
"precisamos de histórias, (...), de narradores, como de pão para a boca. (...) Faz parte da nossa condição humana."

Siri Hustved

\section{Introdução}

Há aproximadamente 40 anos atrás encontrava-me numa aula de Português, no $9^{\circ}$ ano de escolaridade, quando num texto que a minha turma estava a analisar surgiu a palavra estertor. Nenhum dos alunos sabia o seu significado e aguardávamos que o professor José Sampaio nos esclarecesse. Ele começou então a contar um episódio ocorrido na guerra colonial onde tinha participado. Numa saída para o mato onde iria decorrer uma operação militar o seu pelotão avistou subitamente um leão que colocava em perigo os soldados. Alguns deles dispararam sobre o animal e os militares dispersaram rapidamente com medo de um possível ataque. "O animal tombou e todos nós o olhávamos fixamente para ver se ele ainda poderia constituir algum perigo. O leão estremecia e as suas pernas faziam uns movimentos espasmódicos. É isso o estertor, os movimentos finais que antecedem a morte, num animal ou num ser humano."

Passaram-se quatro décadas sobre este episódio, mas eu nunca mais esqueci esta história e o significado de estertor. Agora julgo compreender melhor a razão por que isso sucedeu e o objetivo deste artigo é o de descrever sucintamente uma abordagem que tem ganho alguma proeminência nos últimos anos no âmbito da educação que se designa por ensino narrativo. Todavia, torna-se necessário fazer previamente uma breve incursão pela evolução da psicologia para situarmos histórica e epistemologicamente a questão em análise.

\section{A construção narrativa da realidade}

Em meados da década de 50 uma nova forma de conceber o sujeito psicológico emergiu no campo da psicologia como contraponto ao comportamentalismo que tinha em B. F. Skinner a sua figura tutelar e na teoria do condicionamento operante o seu quadro teórico privilegiado. A psicologia cognitiva, muito influenciada pelo desenvolvimento da cibernética, da teoria da informação e dos computadores, propunha-se analisar os seres humanos como processadores de informação, recebendo inputs do meio e produzindo outputs. Desta forma, as variáveis e os processos psicológicos internos envolvidos em áreas tão distintas como a atenção, a memória ou a perceção, por exemplo, começaram a ser objeto de investigação, algo que o comportamentalismo, centrado numa conceção positivista de ciência e no comportamento observável, tinha afastado do campo da investigação psicológica (BRUNER, 1997). 
A psicologia cognitiva, na sua primeira fase, colocava grande ênfase em estudar a forma como as pessoas, definidos como agentes racionais, manipulavam símbolos abstratos por intermédio de um processo de computação algorítmica, subordinada à razão e a uma lógica universal, que constituiria a forma privilegiada de aceder à realidade (GONÇALVES, 2000). A partir dos anos 80 esta forma de conceber o sujeito psicológico começou a ser contestada a partir de várias perspetivas. A construção de significados passou a ser concebida como a dimensão privilegiada a partir da qual os seres humanos dotam de sentido e coerência o universo em que habitam. No âmbito desta viragem conceptual, que se afasta de um essencialismo naturalista e que enfatiza a dimensão subjetiva, autopoiética e social da construção psicológica da realidade, a narrativa emergiu como um dos mais interessantes modelos do funcionamento psicológico.

Polkinghorne (1988) definiu narrativa como "uma estrutura de significado que organiza acontecimentos e ações humanas num todo, atribuindo desta forma significado às ações e acontecimentos individuais de acordo com o seu efeito na totalidade" (p. 18). Esta definição capta algumas caraterísticas que exploraremos mais à frente, mas importa por agora clarificar que iremos usar os termos história e narrativa como sinónimos aproximados, embora alguns autores sustentem que o primeiro consiste na descrição de um acontecimento específico, individual ou coletivo, que é estruturado de forma a distinguir um início, um meio e um fim, enquanto que o segundo é um termo mais abrangente que pode ser formado por várias histórias e comentários sobre as mesmas (BRAKKE, HOUSKA, ZHAO, KINSLOW, CLINTON \& CAMPBELL, 2015; MCLEOD, 1997).

Devemos a Jerome Bruner (1986) uma distinção particularmente profícua entre dois tipos de cognição, a cognição paradigmática e a cognição narrativa. A linguagem científica constitui um exemplo perfeito da primeira. Nela o objetivo visa atingir uma descrição e explicação do mundo de natureza matemático-formal que emprega categorias que, devidamente articuladas entre si, formam sistemas que descrevem uma determinada realidade. A ênfase é colocada na identificação de fatores causais e no desenvolvimento de procedimentos lineares e proposicionais, assentes na coerência e na não contradição, que pretendem avaliar a sua verdade empírica através da corroboração ou de infirmação de hipóteses empiricamente testáveis.

$\mathrm{Na}$ cognição narrativa, por outro lado, o que se pretende é contar boas histórias e o critério para as avaliar não reside tanto na sua verdade ou falsidade, mas essencialmente na sua verossimilhança. Seria através da construção e da partilha de narrativas que o sujeito psicológico alicerça o seu modo privilegiado de compreender a realidade, nomeadamente a forma como se perceciona a si próprio. O self pode ser concebido como o resultado de um processo narrativo que os indivíduos recorrem para dar conta do seu percurso biográfico e da sua identidade. Este trabalho de produção narrativa deve ser entendido como um procedimento que nunca está completamente finalizado. Como afirmam Vieira e Henriques (2014) a identidade não é "(...) algo que emerge na adolescência de maneira acabada, mas está sempre sendo construída e reconstruída. Ela pode ser entendida como uma narrativa aberta, nunca totalmente concluída, ou como uma antologia de histórias mais ou menos integradas e coerentes acerca da vida de uma pessoa. O caráter distintivo destas narrativas é a sua tendência à unidade e à coerência" (p. 167). O nosso percurso de vida, que se expressa na identidade de cada um, não passaria de um conjunto de experiências mais ou menos 
caóticas se não as enquadrássemos numa estrutura narrativa que as organize num determinado contexto a partir do qual possamos atribuir-Ihes um significado (GONÇALVES, 2003). Como Howard (1991) sintetizou, na cognição narrativa enfatiza-se o homo fabulus em detrimento do homo scientus.

Quando nos debruçamos sobre a forma como a realidade é construída e partilhada facilmente constatámos que em muitas instâncias ela se encontra organizada de forma narrativa. Ao nível individual os seres humanos estão constantemente a produzir e a partilhar narrativas sobre as suas vidas uns com os outros (AVRAAMIDOU \& OSBORNE, 2009). De facto, é muito comum iniciar uma conversa com uma pessoa e de imediato a situarmos num plano narrativo. Pode ser algo como "Nem queiras saber o que me aconteceu hoje!" ou "Conheci ontem uma pessoa que me contou uma história interessante sobre ti.", seguindo-se uma descrição de uma ou mais histórias. Podemos igualmente constatar que no plano social é a organização narrativa que predomina. É o caso, por exemplo, no âmbito religioso, da descrição da criação do mundo que encontrámos no Génesis do Velho Testamento ou das parábolas de Jesus de Nazaré nos Evangelhos.

Se podemos concluir, pelo menos provisoriamente, que grande parte da cognição humana se estrutura de forma narrativa, convém especificar alguns dos elementos que a definem com o objetivo de compreender de forma mais aprofundada como ela nos possibilita perceber o mundo em que habitamos. A narrativa permite, em primeiro lugar, estabelecer a sequencialidade e a temporalidade de um ou mais acontecimentos (BRUNER, 1997). A experiência humana é por vezes confusa e desorganizada, pelo que se torna necessário dotá-la de algum tipo de organização. Quando contámos histórias sobre nós próprios ou sobre os outros estamos a organizar uma experiência numa determinada sequência e a situá-la temporalmente. A narrativa possibilita elencar os eventos de forma sequencial identificando um início, um desenvolvimento e um desfecho. E o enredo que organiza a narrativa permite, igualmente, situá-la num determinado momento no tempo, mais próximo ou mais distante.

Uma outra dimensão essencial para se compreender a narrativa, seja sobre o self ou sobre o mundo, é que ela não se realiza num vácuo social, bem pelo contrário. É por intermédio das ferramentas que a cultura disponibiliza num determinado tempo histórico-social que os indivíduos produzem as suas histórias. Estas devem ser compreendidas no âmbito de narrativas mais vastas, histórica e culturalmente situadas, onde se fundam as formas e os processos inerentes à narração. De facto, qualquer processo narrativo assenta na linguagem, dispositivo que, por definição, é socialmente constituído e partilhado. Por outro lado, as narrativas que os indivíduos produzem só fazem sentido se têm alguém a quem são contadas porque não existe uma narrativa sem um narrador e sem um público que a escute. Ou seja, por outras palavras, toda a narrativa não deve ser vista como um ato puramente individual, mas sim como o resultado de uma produção discursiva que a situa num determinado contexto cultural específico donde ela emerge e na qual adquire um determinado sentido. Como afirmou Gonçalves (2000) a "narrativa cumpre (...) uma dupla função (...) a de organizar simultaneamente a experiência individual e a experiência social" (p. 55).

É ainda importante sublinhar que as narrativas não devem ser necessariamente avaliadas a partir de critérios de verdade ou falsidade que são prevalecentes no discurso científico que se funda na cognição paradigmática, como já tivemos a oportunidade de referir (BRUNER, 1997). Muitos dos 
mitos fundadores prevalecentes em inúmeras culturas são historicamente falsos, mas nem por isso deixam de servir como referenciais que organizam a experiência humana de determinadas comunidades. Por outro lado, as narrativas presentes em obras de criação artística, como no cinema ou na literatura, têm muitas vezes um alcance bem mais profundo e duradouro do que histórias que se fundam em acontecimentos reais. A personagem de D. Quixote criada por Miguel de Cervantes ou de Hamlet por William Shakespeare, por exemplo, continuam a exercer um fascínio secular apesar de não passarem de criações literárias e são muitas vezes invocadas para compreender determinadas situações com que os seres humanos se confrontam.

Provavelmente a caraterística mais importante da narrativa é que ela possibilita dotar de significado o mundo que os seres humanos habitam. No campo da psicologia a psicoterapia existencial será provavelmente a abordagem que colocou a busca do sentido como a dimensão mais importante da existência humana. Devemos a Viktor Frankl (2012) uma das mais realistas e dramáticas descrições dos campos de concentração nazis dos quais ele foi um dos sobreviventes. Mesmo nas condições mais extremas onde a esperança parecia ser completamente absurda, a sobrevivência implicava procurar um sentido num quotidiano marcado por um sofrimento físico e psicológico que nos é difícil compreender. Como Frankl escreveu em O Homem em Busca de um Sentido: "A busca de sentido por parte do Homem é a motivação essencial da sua vida (...). O sentido é único e específico na medida em que ele tem que ser preenchido, e pode ser preenchido, somente por ele; só então assume um significado capaz de satisfazer a sua própria vontade de sentido" (pp. 102-103). A organização narrativa da experiência implica um processo de significação, sempre aberto e sujeito a reformulações face à natureza complexa e multifacetada da experiência, sem o qual os seres humanos têm uma enorme dificuldade em habitar o mundo em que vivem.

\section{Narrativa, ensino e aprendizagem}

No seu sentido mais lato, podemos definir aprendizagem como "uma experiência [que] causa uma mudança relativamente permanente no comportamento ou conhecimento de um indivíduo" (WOOLFOLK, HUGHES \& WALKUP, 2008, p. 244). Podemos distinguir três grandes abordagens psicológicas sobre a aprendizagem: as comportamentais, centradas nos processos através dos quais determinados estímulos do meio reforçam ou punem comportamentos; as cognitivistas, que privilegiam variáveis psicológicas internas que codificam, transformam e armazenam informação; e as construtivistas, que sustentam que o conhecimento implica um processo de construção no qual o indivíduo, de forma ativa e em interação permanente com o meio, desenvolve estruturas psicológicas gradualmente mais complexas a partir das quais atribui um significado à realidade. A utilização de histórias no contexto educativo possibilita que os alunos se envolvam num processo de construção de significados que pode ser interpretado como uma estratégia construtivista ao nível do ensino e da aprendizagem (AVRAAMIDOU \& OSBORNE, 2009; SZURMAK \& THUNA, 2013).

Uma abordagem pedagógica que recorre a narrativas como forma de facilitar aprendizagens duradouras e significativas por parte dos estudantes apresenta várias caraterísticas que devem ser realçadas. Em primeiro lugar, possibilita ancorar conceitos abstratos em casos concretos e mais 
imediatos facilitando, desta forma, a ligação entre a teoria e a prática (Koenig \& Zorn, 2002; Santos, 2017; Szurmak \& Thuna, 2013). Por outro lado, a utilização de histórias fornece uma contextualização ao providenciar o enquadramento a partir do qual o novo conhecimento pode ser integrado em esquemas psicológicos que os indivíduos já possuem, aumentando a sua capacidade de compreensão e de retenção (AVRAAMIDOU \& OSBORNE, 2009; MILLER \& WOZNIAK, 2015; Santos, 2017). Uma outra caraterística particularmente relevante prende-se com a dimensão emocional que as narrativas possibilitam (MILLER \& WOZNIAK, 2015). Embora estejamos ainda longe de perceber em toda a sua complexidade a relação entre emoções e aprendizagem (HASCHER, 2010), é razoável pressupor que a ressonância emocional de uma narrativa desempenha um papel importante na compreensão de material novo com que os alunos se confrontam. Por fim, as histórias permitem um meio privilegiado de conhecer o mundo de outras pessoas, principalmente quando o registo narrativo se situa numa dimensão biográfica, possibilitando contrastar modos de análise e de ação de uma ou mais personagens com a pessoa que escuta a narrativa (CHAN, 2012).

As estratégias específicas que recorrem às narrativas no contexto do ensino são demasiado diversas e numerosas para serem objeto de uma descrição sistemática e exaustiva no âmbito dos limites do presente texto, pelo que nos limitaremos a descrever alguns estudos que consideramos representativos do ensino narrativo. Deveremos sublinhar, contudo, que defender uma abordagem narrativa não implica, como deverá ser óbvio, abandonar outras estratégias pedagógicas que os professores já utilizam comummente nas suas aulas, mas sim complementá-las (AVRAAMIDOU \& OSBORNE, 2009).

A utilização de estratégias narrativas que se baseiam em obras de cariz artístico, ao nível da literatura ou do cinema, só para referir estes dois domínios, pode constituir um relevante recurso didático suscetível de ser mobilizado para potenciar aprendizagens significativas por parte dos alunos. Reigada (2016), por exemplo, descreveu de que forma utilizou um filme baseado em acontecimentos reais ocorridos no decurso da Guerra Fria com o objetivo de diversificar as fontes a partir das quais uma determinada unidade didática foi lecionada com uma amostra de alunos de História do $3^{\circ}$ ciclo do ensino básico. Nas suas palavras, "uma das principais potencialidades do filme consiste exatamente na eventualidade dele desenvolver um conjunto de atividades ligadas à capacidade de comunicação escrita e oral. Se a este facto juntarmos a possibilidade de utilizar o filme com outras fontes, nomeadamente escritas, gráficas ou iconográficas, estamos não só a dinamizar o filme enquanto recurso, mas também a proceder a uma diversificação de estratégias que contribuem para um importante enriquecimento interpretativo que se manifestará numa maior capacidade argumentativa" (p. 85). No estudo de caso descrito pelo autor foi possível constatar um desempenho académico superior nas turmas em que o filme foi exibido e explorado do que nas turmas em foram utilizados somente os recursos didáticos tradicionais.

Com o objetivo de avaliar a utilização de narrativas como recurso pedagógico para ensinar a teoria da seleção natural em turmas do ensino secundário, Prins, Avraamidou e Goedhart (2017) recorreram a dois grupos de estudantes. Em ambos os grupos foi utilizado um texto em formato narrativo para explicar as caraterísticas da seleção natural. A intervenção implicou uma primeira aula 
em que o texto em formato narrativo foi explorado, seguindo-se a aplicação de um questionário para avaliar diversas dimensões do conhecimento adquirido e, num último momento, um período de discussão sobre o tema da seleção natural. Uma semana depois os estudantes foram novamente avaliados com o mesmo questionário com o objetivo de testar o processo de memorização dos conteúdos abordados. A investigação, incluiu, igualmente a observação das aulas pelos investigadores, uma entrevista aos professores e várias entrevistas a alunos. Os resultados revelaram que o formato narrativo possibilitou uma elevada percentagem de informação correta memorizada e, para a maioria dos alunos, constituiu uma experiência educativa enriquecedora, leitura corroborada pela opinião dos professores envolvidos na investigação. Segundo os autores os "estudantes consideram mais fácil memorizar esquemas cognitivos familiares de conteúdo e formato narrativo do que memorizar géneros discursivos tradicionais, como textos expositivos e argumentativos" (p. 32).

A utilização de estratégias narrativas autobiográficas pode constituir um recurso poderoso que possibilita uma reflexão aprofundada sobre um determinado percurso de vida. No âmbito de cursos de formação inicial de professores Reeves (2013) propôs aos seus alunos a realização de um portefólio digital, com a inclusão de pelo menos dez imagens diferentes e uma narração áudio, que ilustrasse a influência da cultura onde foram criados no seu processo de construção identitário. Como ponto de partida a professora disponibilizava o seu próprio portefólio, o que facilitava a criação de um clima relacional de confiança para os estudantes partilharem com a docente e com os seus colegas reflexões sobre o seu percurso de vida que possivelmente não revelariam noutras circunstâncias. Esta tarefa, apesar de ter um objetivo definido, não prescrevia um processo sequencial bem estruturado e organizado, o que obrigava os alunos a lidar com sentimentos de ansiedade e mesmo de resistência que tinham que ser ultrapassados para que fosse possível encontrar um sentido de autoria nos trabalhos que produziram. Embora a autora não tivesse utilizado um procedimento formal para avaliar o impacto da utilização de portefólios na aprendizagem dos alunos, ela concluiu que as suas reflexões possibilitaram uma compreensão mais aprofundada da diversidade cultural e do papel desempenhado pela cultura no processo de construção da identidade dos estudantes.

Uma outra investigação realizada por com alunos do $9^{\circ}$ e do $10^{\circ}$ anos procurou avaliar o impacto da utilização de narrativas biográficas de três cientistas famosos, Albert Einstein, Marie Curie e Michael Faraday, na sua motivação e realização académicas (LIN-SIEGLER, AHN, CHEN, FANG \& LUNA-LUCERO, 2016). As narrativas utilizadas no estudo, num total de nove, pertenciam a três categorias distintas: histórias que descreviam os feitos científicos alcançados pelos cientistas, histórias que se centravam nas dificuldades de natureza intelectual que tiveram que ultrapassar e, finalmente, histórias relacionadas com as dificuldades ao nível das suas vidas pessoais. Os resultados deste estudo permitiram concluir que as narrativas que abordavam as dificuldades intelectuais e pessoais dos três cientistas tiveram um impacto positivo ao nível da realização académica e da motivação dos alunos, principalmente junto do grupo de estudantes de menor rendimento. Os sujeitos da amostra identificaram-se mais com as personagens escolhidas quando as histórias se centravam nos obstáculos que tiveram que ultrapassar do que nas descobertas científicas 
que os tornaram famosos, provavelmente porque desta forma é mais fácil encontrar paralelismos entre os dois tipos de percursos biográficos.

\section{Conclusão}

No presente texto procurei demonstrar como a utilização de narrativas constitui um meio poderoso que pode ser utilizado ao nível do ensino como uma estratégia suscetível de promover aprendizagens significativas e duradouras. A partir da proposta de Bruner (1986, 1990), que defende que a cognição narrativa desempenha um papel central no processo como os seres humanos procuram compreender o mundo em que habitam, sustentei que uma pedagogia narrativa possibilita um espaço de co(construção) de significados) sobre diferentes conteúdos que são abordados nas diversas disciplinas do currículo.

Não pretendo defender, como já sublinhei, que a utilização de estratégias narrativas na educação possa configurar-se como a solução para os problemas do ensino e da aprendizagem com que as escolas dos nossos dias se debatem, mas tão só como uma abordagem que pode ser explorada, de formas muito diversas, para atingir objetivos educacionalmente relevantes. Justifica-se prosseguir a investigação neste domínio com o objetivo de identificar e mapear os processos específicos do ensino narrativo que se encontram associados a melhores resultados ao nível das aprendizagens dos estudantes, uma área ainda pouco explorada ao nível da investigação educacional.

\section{Bibliografia}

AVRAAMIDOU, I., \& OSBORNE, J. (2009). The role of narrative in communicating science. International Journal of Science Education, 31 (12), 1683-1707.

BRAKKE, K., HOUSKA, J. A., ZHAO, X., KINSLOW, S., CLINTON, A., \& CAMPBELL, B. (2015). The power of story as an instructional strategy. In K. Brakke \& J.A. Houska (Eds.), Telling stories: The art and science of storytelling as an instructional strategy (pp. 7-13). Disponível em http://teachpsych.org/ebooks/ [Acedido em 2 de julho de 2018]

BRUNER, J. S. (1986). Actual minds, possible worlds. Cambridge: Harvard University Press.

BRUNER, J. S. (1997). Actos de significado. Lisboa: Edições 70.

CHAN, E. Y. (2012). The transforming power of narrative in teacher education. Australian Journal of Teacher Education, 37 (3), 111-127.

FRANKL, V. E. (2012). O homem em busca de um sentido. Alfragide: Lua de Papel.

GONÇALVES, M. M. (2003). Psicoterapia, uma arte retórica: Contributos das terapias narrativas. Coimbra: Quarteto.

GONÇALVES, O. F. (2000). Viver narrativamente. Coimbra: Quarteto.

HASCHER, T. (2010). Learning and emotion: Perspectives for theory and research. European Educational Research Journal, 9 (1), 13-28.

HOWARD, G. S. (1991). Culture tales: A narrative approach to thinking, cross-cultural psychology, and psychotherapy. American Psychologist, 46 (3), 187-197.

KOENIG, J. L., \& ZORN, C. R. (2002). Using storytelling as an approach to teaching and learning with diverse students. Journal of Nursing Education, 41 (9), 393-399. 
LIN-SIEGLER, X., AHN, J. N., CHEN, J., FANG, F. A., \& LUNA-LUCERO, M. (2016). Even Einstein struggled: Effects of learning about great scientists' struggles on high school students' motivation to learn science. Journal of Educational Psychology, 108 (3), 314-328.

MCLEOD, J. (1997). Narrative and psychotherapy. London: Sage.

MILLER, R. L., \& WOZNIAK, W. J. (2015). Weaving yarns into good psychological science education. In K. Brakke \& J.A. Houska (Eds.), Telling stories: The art and science of storytelling as an instructional strategy (pp. 27-39). Disponível em http://teachpsych.org/ebooks/ [Acedido em 23 de julho de 2018]

POLKINGHORNE, D. E. (1988). Narrative knowing and the human sciences. Albany: State University of New York Press.

PRINS, R., AVRAAMIDOU, I., \& GOEDHART, M. (2017). Tell me a story: The use of narrative as a learning tool for natural selection. Educational Media International, 54 (1), 20-33.

REEVES, A. L. (2013). Selves, lives, and videotape: Leveraging self-revelation through narrative pedagogy. New Directions for Teaching and Learning, Fall, 55-60.

REIGADA, T. S. (2016). Ensinar com a sétima arte: O espaço do cinema na didática da História. In Isabel Barca \& Luís Alberto Marques Alves (Coords.), Educação histórica: Perspetivas de investigação nacional e internacional (pp. 73-90). Porto: CITCEM.

SANTOS, P. J. (2017). Pedagogia no ensino superior: Três propostas modestas. In Fernando

Remião, José Fernando Oliveira, Luís Castro, Maria Amélia Ferreira, Patrícia Rosado Pinto \& Rita Cadima (Eds.), Livro de Atas do CNaPPES 2016 - Congresso Nacional de Práticas Pedagógicas no Ensino Superior (pp. 355-360). Lisboa: CNaPPES.

SZURMAK, J., \& THUNA, M. (2013). Tell me a story: The use of narrative as a tool for instruction. In D. M. Mueller (Ed.), Imagine, innovate, inspire: Atas da Association of College \& Research Libraries 2013 Conference (pp. 546-552). Disponível em http://www.ala.org/acrl/sites/ala.org.acrl/files/content/conferences/confsandpreconfs/2013/paper s/SzurmakThuna_TellMe.pdf [Acedido em 30 de abril de 2018]

VIEIRA, A.G., \& HENRIQUES, M. R. (2014). A construção narrativa da realidade. Psicologia: Reflexão e Crítica, 27 (1), 163-170.

WOOLFOLK, A., HUGHES, M., \& WALKUP, V. (2008). Psychology in education. Essex: Pearson. 